\title{
EL COMPLEJO «SANTUARIO-MERCADO-FESTIVAL» Y EL ORIGEN DE LOS CENTROS CEREMONIALES EN EL ÁREA ANDINA SEPTENTRIONAL*
}

\author{
POR \\ JOSÉ ALCINA FRANCH \\ Universidad Complutense de Madrid
}

\begin{abstract}
En este ensayo se aborda el problema de los orígenes del urbanismo en el área andina, entendiendo que tal urbanismo se concreta en los "centros ceremoniales», considerados como ciudades prístinas o alternativas, cuyos orígenes hay que verlos en relación con lugares en los que se alcanza un estado de paz concertada de carácter «internacional» y en los que coinciden intereses religiosos (un santuario), económicos (un mercado) y donde se celebran festivales cuya motivación y función son múltiples: redistribución exogamia, etc.
\end{abstract}

El tema que vamos a desarrollar en las páginas que siguen aborda, una vez más, el problema de los orígenes del urbanismo en los Andes, para el que tantas y tan importantes contribuciones ha ofredido Richard P. Schaedel en los últimos cuarenta años ${ }^{1}$. La hipótesis

* Este artículo fue elaborado y presentado como contribución al Homenaje que se preparaba en 1990 al Prof. Richard P. Schaedel. Habiendo transcurrido siete años sin saber el destino de aquel Homenaje y dado que me he referido a este trabajo en múltiples ocasiones, he decidido publicarlo con independencia de que aquel Homenaje se edite algún día y considerándolo, siempre, como un homenaje personal al Dr. Schaedel.

1 Richard P. SCHAEDEL, «Maior ceremonial and population centers. The lost cities of Perú», Scientific American, vol. 185, 2, 1950, pp. 18-23; «Incipient urbanization and secularization in Tiahuanacoid Perú», American Antiquity, vol. 31, Salt Lake City, 1966, pp. 338-344; «On the definition of civilization, city and town in prehistoric America. XXXVII Congreso Internacional de Americanistas, Buenos Aires, 1969; «The city and the origin of the state in America», Urbanización y proceso social en América (HARDOY-SCHAEDEL, eds.), Lima, 1972, pp. 15-33; «The birth of cities in the Andes», La Ciudad Iberoamerica$n a$, Madrid, 1987, pp. 55-80. R.P. SCHAEDEL y Duccio BoNAVIA, «Patrones de urbanización incipiente en los Andes centrales y su continuidad», Asentamientos urbanos y organi- 
que se presentará a lo largo de este ensayo ya fué anticipada en un estudio anterior ${ }^{2}$ ampliándose en esta ocasión de manera que quede suficientemente definido el complejo que estamos llamando, «santuario-mercado-festival».

Para la presentación de esta hipótesis, vamos a tomar como base nuestros trabajos de investigación en el área andina septentrional, tanto en Atacames, en la costa del Ecuador ${ }^{3}$, como en Ingapirca, en el altiplano ${ }^{4}$, así como los estudios en curso sobre la tipología y evolución de las jefaturas (chiefdoms) en las áreas del Caribe, Centroamérica y los Andes Septentrionales ${ }^{5}$ en el marco del estudio del urbanismo precolombino.

La formulación de la hipótesis que vamos a desarrollar en estas páginas se podría hacer en la forma siguiente: si entendemos que los llamados «centros ceremoniales», constituyen una forma de urbanismo alternativo o prístino de las ciudades, sus orígenes hay que verlos en relación con lugares en los que se alcanza un estado de paz concertada de caracter «internacional», en los que coinciden intereses religiosos -un santuario-, económicos -un mercado- y donde se celebran festivales, cuya motivación y función son múltiples, según veremos más adelante.

Aunque es imposible e impertinente que profundicemos aquí, en temas tan discutidos como los de urbanismo y civilización, conviene que contemos desde el principio con una definición suficiente acerca del término «urbanismo». Utilizaremos para ello la que proporcio-

zación socioproductiva en la historia de América Latina, Buenos Aires, SIAP, 1977, pp. 15-39.

José Alcina Franch, «Orígenes del urbanismo en el Area Andina Septentrional», Atti del Convegno Internazionale: Archeologia Scienza e Societa nell'America Precolombina, Brescia, 1989, pp. 166-173.

3 José AlCINA FRANCH, La Arqueología de Esmeraldas (Ecuador). Introducción general. Memorias de la Misión Arqueológica Española en el Ecuador, Vol. 1, Madrid, 1979, «El modelo teórico de «jefatura» y su aplicación al área andina septentrional norte», $A r$ queología y Etnohistoria del Sur de Colombia y el Norte del Ecuador (ALCINA-MORENO comps.), Guayaquil, 1986, pp. 265-288.

4 José Alcina Franch, «Los indios cañaris de la Sierra Sur del Ecuador», Miscelánea Antropológica Ecuatoriana. Vol. 6, Guayaquil, 1987, pp. 141-188; «Cooperación política en Mesoamérica y los Andes en época precolombina», Revista de Indias. Vol. LV, núm. 204, Madrid, 1995, pp. 279-300.

5 José AlCINA FranCH, «El concepto de jefatura en el contexto de la evolución social». Arbor, Tomo 123, núm.482, Madrid, 1986, pp. 35-54. J. Alcina y Josefina Palop, «En torno al concepto de «jefatura». Il Congreso Iberoamericano de Antropología: Las Palmas de Gran Canaria, 1985, pp. 137-155.

R. I., $1999, \mathrm{n}^{\circ} 215$ 
nan William T. Sanders y Bárbara Price ${ }^{6}$, según los cuales, el urbanismo puede definirse como el proceso por el cual comunidades físicas surgen con grandes poblaciones que se concentran en un área pequeña continua y compacta y están caracterizadas por una intensa diferenciación interna basada en variaciones de riqueza, especialización económica y poder. Estas características —crecimiento de población, nucleación y diferenciación social- pueden ser convenientemente analizadas como procesos separados pero interrelacionados». Los criterios utilizados por Sanders y Price apuntan a tres aspectos fundamentales en el proceso de urbanización: demografía, concentración de población y complejidad social y no meramente a los que proporciona el urbanismo más tradicional y mecánico.

En cualquier caso, el urbanismo es un proceso para cuyo surgimiento se requiere una serie de prerrequisitos, entre los que cabría mencionar: la productividad de la agricultura de irrigación, el control centralizado de los sistemas de riego y las instituciones que armonizan los intereses de agricultores y pastores, etc. ${ }^{7}$ pero sobre todo, la presencia y el peso político del Señor, Rey o Soberano, quien ejerce un papel catalizador para el nacimiento del urbanismo.

Es evidente que, como veremos luego, el desarrollo de las jefaturas implica la concentración en la «cabecera» no sólo del Cacique y su parentela, sino de los especialistas a su servicio, incluida la nueva milicia que se desarrolla en su torno, lo que implica a su vez, la construcción de instalaciones especiales: palacios, templos, fortalezas y viviendas. Todas estas instalaciones que originalmente no sobrepasan en mucho el volumen de las viviendas ordinarias de los habitantes de aquel núcleo de población, conforme va aumentando el carácter suntuario de las mismas para proporcionar más y más prestigio a sus habitantes, crean el núcleo religioso, político y administrativo del centro cívico en torno al que se aglutinará la ciudad propiamente dicha. El hecho de que muchos de esos centros se hallen planificados permite concluir que «fue el previo desarrollo político lo que hizo posible la ciudad y no al contrario» ${ }^{8}$.

\footnotetext{
6 W.T. SANDERS y Bárbara PRICE, Mesoamérica. The evolution of a Civilization, New York, Random House, Studies in Anthropolopy, 1968, p. 46.

7 Robert M. ADAMS, «The origin of cities. Civilization», Scientific America, San Francisco, 1979 [1960], pp. 11-17 [pp. 13-14].

8 Elman SERVICE, Los orígenes del Estado y de la civilización, Madrid, Alianza Universidad. Textos: 83, 1984, p. 305.
} 
EL PROCESO URBANÍSTICO.

Si consideramos que el crecimiento demográfico, el aumento de la concentración de población y el incremento de la complejidad social son procesos paralelos que representan un continuum podremos entender que el establecimiento de tipologías de los asentamientos representa, al mismo tiempo, la determinación de los escalones de esa secuencia o proceso.

El estudio comparativo de la obra de una serie de autores nos ha permitido proponer la secuencia que queda reflejada en el Cuadro 1 y que mencionamos a continuación, marcando los términos máximos y mínimos de población en cada caso:

\section{CUADRo 1}

\begin{tabular}{|c|c|c|c|c|c|c|c|}
\hline $\begin{array}{c}\text { Rowe } \\
1963 \\
\end{array}$ & $\begin{array}{c}\text { Sanders } \\
1961 \\
\end{array}$ & $\begin{array}{c}\text { Borhegyi } \\
1966\end{array}$ & $\begin{array}{c}\text { Dewey } \\
1966\end{array}$ & $\begin{array}{l}\text { Wolfe } \\
1966 \\
\end{array}$ & $\begin{array}{c}\text { Lanning } \\
1967\end{array}$ & $\begin{array}{c}\text { Schaedel } \\
1969 \\
\end{array}$ & Alcina \\
\hline \multirow{2}{*}{$\begin{array}{l}\text { Centro } \\
\text { Urbano } \\
\text { Grande } \\
2.000 \\
\end{array}$} & & $\begin{array}{c}\text { Centros } \\
\text { ceremoniales } \\
\text { mayores }\end{array}$ & & 10.000 & & 50.000 & $\begin{array}{l}\text { Urbe } \\
10.000\end{array}$ \\
\hline & $\begin{array}{l}\text { Ciudad } \\
10.000\end{array}$ & $\begin{array}{c}\text { Centros } \\
\text { ceremoniales } \\
\text { Menores }\end{array}$ & $\begin{array}{c}\begin{array}{c}\text { Gran } \\
\text { ciudad }\end{array} \\
5.000\end{array}$ & $\begin{array}{l}\text { Ciudad } \\
2.500\end{array}$ & $\begin{array}{l}\text { Ciudad } \\
5.000\end{array}$ & $\begin{array}{l}\text { Ciudad } \\
25.000\end{array}$ & $\begin{array}{l}\text { Ciudad } \\
2.5 \mathrm{C0}\end{array}$ \\
\hline Centro & $\begin{array}{c}6.000 \\
\text { Villas } \\
\text { Urbanas } \\
3.000 \\
\end{array}$ & $\begin{array}{c}\text { Pueblos } \\
\text { agricolas } \\
\text { satélites } \\
500 \\
\end{array}$ & $\begin{array}{c}\begin{array}{c}\text { Pequeña } \\
\text { ciudad }\end{array} \\
1.000 \\
\end{array}$ & $\begin{array}{c}\text { Pueblo } \\
1.000 \\
\end{array}$ & $\begin{array}{l}\text { Villa } \\
1.000 \\
\end{array}$ & $\begin{array}{l}\text { Villa } \\
2.000 \\
\end{array}$ & $\begin{array}{l}\text { Villa } \\
1.000 \\
\end{array}$ \\
\hline \multirow[t]{3}{*}{$\begin{array}{l}\text { Urbano } \\
\text { Pequeño }\end{array}$} & \multirow[t]{3}{*}{$\begin{array}{l}\text { Comunidades } \\
\text { rurales } \\
\text { pequeñas }\end{array}$} & $\begin{array}{c}\text { Pueblos } \\
\text { agrícolas } \\
\text { dispersos } \\
250\end{array}$ & $\begin{array}{l}\text { Pueblo } \\
250\end{array}$ & $\begin{array}{c}\begin{array}{c}\text { Aldea } \\
\text { grande }\end{array} \\
200\end{array}$ & \multirow[t]{3}{*}{ Aldea } & & $\begin{array}{l}\text { Pueblo } \\
250\end{array}$ \\
\hline & & $\begin{array}{c}100 \\
\text { Aldea } \\
25 \\
\end{array}$ & \multirow[t]{2}{*}{ Aldea } & $\begin{array}{c}\text { Aldea } \\
20 \\
\end{array}$ & & & $\begin{array}{c}\text { Aldea } \\
25 \\
\end{array}$ \\
\hline & & & & & & & Campamento \\
\hline
\end{tabular}

R. I., $1999, \mathrm{n}^{\circ} 215$ 
[1] Campamento: menos de 25 habitantes.

[2] Aldea: 25-250 habitantes.

[3] Pueblo: 250-1000 habitantes.

[4] Villa: 1000-2500 habitantes.

[5] Ciudad: 2500-10.000 habitantes.

[6] Urbe: más de 10.000 habitantes.

El surgimiento del urbanismo, al que nos referimos en este ensayo, afecta fundamentalmente al tipo de población que denominamos villa, ya que los pueblos o aldeas grandes, con una población por debajo de los mil habitantes, debemos considerarlos como típicamente rurales y las ciudades estarían plenamente integradas en el concepto de lo urbano. El asentamiento que estamos denominando villa y que ya tiene cierto carácter semiurbano, siendo el tipo característico de las jefaturas, es el que recibe denominaciones más variadas: «pueblo», «pequeña ciudad» o «pueblo agrícola satélite».

No nos vamos a detener en la definición de lo que es una villa, o de los componentes del registro arqueológico de una jefatura, ya que nos hemos ocupado del tema en varias ocasiones anteriores ${ }^{9}$ en relación con los tainos ${ }^{10}$ los cañaris ${ }^{11}$ y los atacameños ${ }^{12}$; nos vamos a detener, aunque sea de manera breve, en la vieja discusión acerca de la supuesta oposición entre centro ceremonial y ciudad, ya que nuestro planteamiento se refiere al surgimiento del urbanismo, precisamente en la forma de centro ceremonial.

En ese sentido, hay que destacar en primer lugar, como ya lo hemos dicho en párrafos anteriores, que el urbanismo es un proceso dentro del continuum de los sistemas de asentamiento, que ordinariamente surge entre lo que estamos llamando villa y la ciudad; en algún caso hemos hablado de semiurbano ${ }^{13}$ y en otros casos habría

9 José AlCINA FRANCH, «Las jefaturas en perspectiva arqueológica», Espacio y organización social (Adanez-Heras-Varela eds.), Madrid, 1990, pp. 35-56.

10 J. AlCINA y Pedro L. GALAN, «La sociedad taina como una jefatura», IX Congreso Internacional de Arqueología del Caribe (1985), San Juan de Puerto Rico, 1985, En prensa.

11 José AlCINA FRANCH, «Ingapirca: arquitectura y áreas de asentamiento», Revista Española de Antropología Americana, Vol. 8, Madrid, 1978; pp. 127-146; «Los indios cañaris de la Sierra Sur del Ecuador», Miscelánea Antropológica Ecuatoriana, Vol. 6, Guayaquil, 1987, pp. 141-188.

12 José ALCINA FranCH, [3], 1986.

13 J. AlCINA y Remedios de la PEÑA, «Patrones de asentamiento indígena en Esmeraldas durante los siglos XVI y XVII», XLlle. Congrès International des Américanistes, Vol. IX-A, Paris, 1979, pp. 283-301 
que referirse a «asentamientos urbanos», sin que ello implique el tratamiento de ciudad o de centro ceremonial, tal como sucede en Chinchero (Cuzco, Perú), residencia de la «panaca» de Topa Inca Yupanqui ${ }^{14}$

Desde otro punto de vista, hay que destacar que, cuando empleamos la expresión de «verdaderas ciudades» — con casas, calles, callejones, plazas, etc. - estamos implicando la existencia de «falsas ciudades»; esas falsas ciudades serian, por ejemplo, los centros ceremoniales. Como dice Bernal ${ }^{15}$ es difícil pensar en una civilización no urbana y este seria el caso de la civilización maya, si no considerásemos que los centros ceremoniales son equivalentes a las ciudades. Por ello no parece «conveniente dividir la etapa del urbanismo en centros ceremoniales y ciudades urbanas» ${ }^{16}$, aunque Wheatley ${ }^{17}$ argumenta con abundante documentación que la mayor parte de los procesos de urbanismo se iniciaron mediante centros ceremoniales, si bien debieron servir para fines muy diferentes, como de almacenamiento, redistribución, mercado y residencia ${ }^{18}$

Sea el centro ceremonial una primera etapa en el proceso urbanístico, anterior al de las verdaderas ciudades, o una forma de adaptación al medio ambiente de algunas regiones del mundo americano precolombino, o aun del mundo entero, el hecho es que se ofrece con frecuencia en el medio al que estamos aludiendo en estas páginas, por ello conviene disponer de una adecuada definición tal como la que nos proporciona Lanning ${ }^{19}$ para quien los «Centros ceremoniales son un grande y elaborado complejo de estructuras ceremoniales, faltando una población grande y de permanente residencia, que sirve como punto focal para muchos asentamientos sobre una gran área. Los centros ceremoniales representan lo fundamental en nucleación y sincorismo mientras ellos son el núcleo y la mayor parte de la población rural. Habitados permanentemente sólo por un

\footnotetext{
14 José Alcina Franch, Arqueología de Chinchero 1: La arquitectura. Memorias de la Misión Científica Española en Hispanoamérica, Vol. II, Madrid, 1976.

15 Ignacio Bernal, Teotihuacán, Guía oficial, México, INAH-Salvat, 1985.

16 Julio César OLIVE, «Estado, formación socio-económica y periodificación de Mesoamérica», Mesoamérica y el Centro de México (Monjarás et al. eds.), México, 1985, pp. 81-114.

17 Paul WheATLEY, The pivot of the Four Quarters: a preliminary inquiry into the origins and character of the ancient chinese city, Chicago, Aldine, 1971.

18 Elman R. SERVICE, [8].

19 Edward P. LANnIng, Peru before the Incas, New Jersey, Prentice Hall Inc, Englewood Cliffs, 1967, p. 37.
}

R. I., $1999, \mathrm{n}^{\circ} 215$ 
pequeño cuerpo de sacerdotes administradores y personal cuidador eran visitados por la población solamente en ocasiones rituales. Un centro ceremonial puede ser visualizado como la sección nuclear de una ciudad despojada de sus distritos residenciales. Ciudades y centros ceremoniales eran encontrados raramente en la misma región: más bien representan métodos alternativos de organizar la población de una gran área».

La definición de Lanning habría que matizarla en algún sentido, al destacar el hecho de que con bastante frecuencia el centro ceremonial, cuya población interna suele ser escasa, está sostenida por una «población básica de apoyo a veces ralamente diseminada en distancias considerables que acude al centro solamente en ocasiones especiales» ${ }^{20} \mathrm{El}$ ejemplo etnográfico quizás más adecuado y específico para este supuesto es el de los centros ceremoniales de los cayapas actuales, en la cuenca de los ríos Santiago y Cayapa, en la provincia de Esmeraldas, en el Ecuador ${ }^{21}$ No puede desconocerse, sin embargo, que en algún caso - Copán, por ejemplo- junto a los centros ceremoniales conocidos de antiguo, se han descubierto recientemente áreas habitacionales muy extensas ${ }^{22}$ donde aparecieron residencias señoriales, como la de un «escriba», pariente del rey Yax Pac de Copán, o viviendas de artesanos - cesteros, tejedores, marroquineros, etc. - del grupo étnico lenca ${ }^{23}$, lo que apunta a la necesidad de investigar las áreas aledañas de los centros ceremoniales en busca de conjuntos residenciales que, en muchos casos, han debido existir aunque nunca se buscaron.

De otra parte, aunque Lanning afirma que centro ceremonial y ciudad «representan métodos alternativos de organizar la población de una gran área», hay ocasiones en que la convivencia es absoluta. Si consideramos Teotihuacán como un ejemplo típico de «ciudad» del periodo Clásico y Tenochtitlan como lo propio en el periodo Postclásico del Area central de México, tendremos dos casos en los

20 Elman R. SERVICE, [8] p. 304.

21 Isidoro MORENO, «Ecología y sociedad de los Cayapas de Esmeraldas: los patronos de asentamientos», XLII Congrès International des Américanistes, Vol IX-A, Paris, 1979, pp. 319-33.

22 G.R. Willey, R.M. LeVenthal y W.L. Fash, «Maya settlement in the Copan Valley». Archaeology. Vol. 31, [4], New York, 1978, pp. 32-43.

23 D. WeBSTER y Elliot ABRAMS, «An elite compound at Copán, Honduras», Journal of Field Archaeology, Vol. 10, Boston, 1983, pp. 285-96. 
que el «centro ceremonial» convive con la ciudad planeada, refugiándose precisamente en su centro geográfico, a modo de corazón, donde late la vida de la ciudad; en el caso de Tenochtitlan ese centro ceremonial quedaría, además, aislado dentro de un recinto que lo delimita muy claramente.

\section{EL SISTEMA ECONÓMICO.}

En fechas recientes hemos presentado una hipótesis interpretativa del sistema de «jefaturas» en un sentido estrictamente económico, según el cual la redistribución domina absolutamente el conjunto del sistema ${ }^{24}$ No obstante la integración económico-social, según apunta Polanyi ${ }^{25}$ se produce en algunas sociedades, haciendo coincidir los sitemas de reciprocidad, de redistribución y de intercambio ${ }^{26}$ Tal es el caso de las jefaturas, señoríos o curacazgos en los Andes Centrales. En esta región, donde las jefaturas son complejas o avanzadas, hallamos, además, mercados de carácter internacional (Cuadro 2).

En estos casos, el sistema de redistribución es el característico de las jefaturas: las sub-jefaturas - aldeas - asi como los seguidores y familiares que constituyen el grupo privilegiado de los jefes y nobles, proporcionan los bienes que el jefe redistribuye entre todos ellos mediante festivales y otros actos ceremoniales quedándose con una parte - excedente - que es la base para su propio engrandecimiento y progreso, como verdaderos Señores o Caciques. Los bienes acumulados por ese procedimiento se ven incrementados ordinariamente por las acciones de guerra, cuyo botín sirve igualmente para procurar el avance del Señorío en su progreso hacia la constitución del Estado.

La relación entre una jefatura y los señoríos que forman parte de una alianza circunstancial o de una confederación más estable es la que corresponde a la reciprocidad. Esa es la relación entre entidades políticas aliadas en los Andes Centrales - tal es el caso de la guerra de los incas contra los chancas-, área en la que, por otra parte, el

\footnotetext{
24 J. Alcina y Josefina PaloP [5], 1985, y José Alcina FranCh [5], 1986.

25 Karl Polanyi; C.M. AREnSBERg y H.W. PeArson, Comercio y mercado en los imperios antiguos, Labor Universitaria, Barcelona, 1976, pp. 248 y 299.

26 José AlCiNA Franch, «Cooperación política en Mesoamérica y los Andes en época precolombina». Revista de Indias. Vol. LV, núm. 204, Madrid, 1995, pp. 279-300.
}

R. I., $1999, \mathrm{n}^{\circ} 215$ 
concepto de reciprocidad es especialmente característico, constituyendo una arraigada tradición.

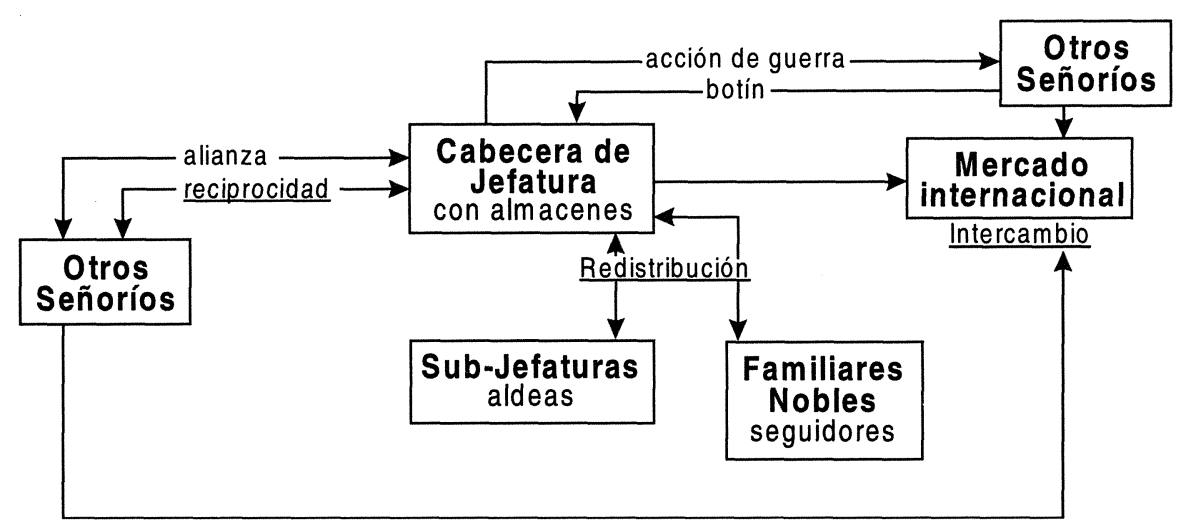

CUADRO 2. Relaciones económicas de una jefatura

Por último, la relación de intercambio se produce entre organismos políticos del género de las jefaturas complejas, cuando aparecen los puertos o mercados internacionales dentro de su propio territorio o en territorios «neutrales», entre varias de esas jefaturas. Es claro que esos mercados no son monetarios, sino que se ejercen a través del sistema de trueque.

Las instituciones de mercado, según las define Polanyi ${ }^{27}$ son «instituciones que comprenden una multitud oferente o una multitud demandante o ambas cosas a la vez. A su vez, las multitudes oferentes o demandantes se definirán como una multiplicidad de sujetos deseosos de adquirir o de deshacerse de productos en el intercambio». Quiere decirse, pues, que aunque el intercambio no es exclusivo del mercado, parece que el mercado es una institución específica del intercambio. Ahora bien, los mercados pueden entenderse como una institución local donde las personas que forman parte de una comunidad intercambien productos, o como una institución «internacional» en la que comunidades diferentes, del mismo grupo étnico -aldeas - o de diferentes grupos, intercambien sus productos. Ta-

27 Karl Polanyi, C. M. Arensberg y H. W. Pearson [25], p. 312. 
les mercados pueden situarse en la «frontera» entre esos grupos o pueden hallarse en el interior de algunos poblados. Según esta clasificación, las aldeas son «centros de vida y convivencia de cada grupo y los mercados centros de intercambio con otros grupos», mientras que en casos diferentes, como ocurre entre los bereberes, «los mercados se encuentran en medio de la población, por lo que, en realidad, estos centros han de considerarse como ciudades mercado que utilizan tanto los campesinos locales como los nómadas que visitan el lugar» ${ }^{28}$.

Es importante hacer observar que, como ya lo hemos indicado más arriba, el mercado y el templo van, generalmente, asociados. Este es el caso de Chinchero (Cuzco, Perú), donde, desde la época de Tupac Yupanqui, el núcleo urbano «parece haber reunido las condiciones necesarias - mercado y templo - para ser, por ello, un centro de atracción para las poblaciones periféricas [que] tienen el núcleo de Chinchero como marco de referencia ceremonial y mercantil» ${ }^{29}$.

Aunque no se trata de un verdadero templo, sino de una estructura a la que tentativamente podemos calificar de «lugar sagrado», sabemos que los tainos acostumbraban a utilizar los juegos de pelota o «bateyes», especialmente los de «la zona central de los pueblos [que] hacían las veces de mercados o ferias para intercambiar productos ${ }^{30}$.

Todos los mercados a los que nos vamos a referir en estas páginas son mercados de trueque, aunque en ocasiones pueda hablarse de una cierta tradición monetaria, más o menos incipiente ${ }^{31}$ Aunque es común interpretar el sistema económico andino, especialmente en la época de la máxima expansión incaica, como un sistema basado en la redistribución estatal, comienza a considerarse como un sistema no exclusivo, con el que convivirían otros de tradición preincaica, en los que el mercado de trueque y el comercio a larga distancia constituirían formas ampliamente utilizadas ${ }^{32}$. El ejemplo que nos ofrece

28 Ibidem, p. 247.

29 Claudio Esteva Fábregat, «Un mercado en Chinchero, Cuzco». Anuario indigenista., Vol. 30:, México, 1970, pp. 213-254, [pp. 214-215].

30 Frank MoYa Pons, «La sociedad taina». Cuadernos de Historia Dominicana. Sto. Domingo, 1973, p. 12. Ricardo E. AlEgRIA, Ball Courts and ceremonial plazas in the West Indies. Yale University Publications in Anthropology, Vol. 79, New Haven, Conn, 1983.

31 Olaf HoLM, «Money axes from Ecuador». Folk, Vols. 8-9, Copenhague, 1966-67.

32 María RostworowsKI, «Mercaderes del Valle de Chincha en la época prehispánica. Un documento y unos comentarios». Revista Española de Antropología Americana. Vol. 5: 135-177, Madrid, 1970; Roswith HARTMANN, «Mercados y ferias prehispánicos en

R. I., $1999, \mathrm{n}^{\circ} 215$ 
en la actualidad el mercado de Chinchero conserva, por lo tanto, «una estructura semejante a la del periodo incáico» ${ }^{33}$, aunque es probable que esa tradición se remonte a una época más antigua que es precisamente la que nos interesa en esta ocasión.

Lo que conocemos como precio «es la definición de relaciones cuantitativas entre productos de diferentes tipos, alcanzada a través del trueque o del regateo» ${ }^{34}$ lo que en definitiva no son más que actos de intercambio que se realizan en el marco del mercado. Para conocer con detalle cómo se realiza el trueque en los mercados andinos tenemos dos testimonios muy explícitos: uno del siglo $\mathrm{XVII}^{35} \mathrm{y}$ otro de nuestras días ${ }^{36}$.

Para Bernabé $\mathrm{Cobo}^{37}$, quien afirma que en el Reino del Perú no se usaba moneda como valor de cambio, el trueque se verificaba en la forma siguiente:

«Como vemos el día de hoy, casi todos los pueblos indios deste reino [del Perú] que los dias de fiesta salen las mujeres a rescatar a las plazas, trayendo cada una la mercadería que tiene: unas sacan fruta, otras maíz, otras carne guisada, otras pescado, carne cruda partida en piezas, sal, coca, ají y deste tono las otras cosas que se contratan; y hacen sus rescates, dando una un plato de fruta por otro de guisado; cuál con ají compra sal; cuál con maíz, carne y así en lo demás; conque todos se proveen de lo que ha menester a trueque de lo que tenían de sobra. Y en verdad que no es mal rato el entretenimiento para los españoles que se hallan presentes, ponerse a mirar cómo se conciertan estos contratos y trueques, en que observa esta gente un modo bien particular, como yo lo he visto hacer algunas veces; es desta forma: ponen las indias toda su mercancía o parte de ella, si es fruta o cosa de este género, hecha montoncitos pequeños en ringlera, de valor de medio o de un real cada montoncillo, si es carne partida en trozos del mismo valor y por este orden las demás cosas. La india que llega a comprar con su maíz en lugar de dinero se asienta muy despacio junto a la vendedora y hace un montoncito de maíz que piensa dar por el precio de lo que compra, sin ha-

\footnotetext{
el área andina», Boletín de la Academia Nacional de Historia. Vol. 54, n 118, Quito, 1971, pp. 214-35. John V. MURRA, La organización económica del Estado inca, Siglo XXI, América Nuestra, 11, México, 1978.

33 Claudio Esteva FÁBrEgat [29], p. 215.

34 Karl Polanyi; C. M. Arensberg y H. W. Pearson, (25), p. 314

35 Bernabé CoBo, Historia del Nuevo Mundo. Biblioteca de Autores Españoles. Tomos 91 y 92, Madrid, 1956, [1653].

36 Claudio Esteva FábRegat [29].

37 Bernabé CoBo [35], vol. II, pp. 24-25.
} 
blarse palabra la una a la otra; la que vende pone los ojos en el maíz y si le parece poco, no dice nada ni hace señal alguna, más que estárselo mirando y mientras está desta suerte, es dar a entender que no se contenta del precio; la que compra tiene puestos los ojos en la vendedora y todo el tiempo que la ve estarse así sesga, va añadiendo a su montoncillo algunos granos más de maíz, que no son muchos; y si todavía esta reacia, añade otras y otras muchas veces, pero siempre muy poca cosa, hasta que la que vende se contenta del precio y declara su beneplácito no de palabra, que desde el principio al cabo no se dicen ninguna, aunque dure el conformarse media hora, sino de hecho, extendiendo la mano y recogiendo para sí el maiz... ${ }^{38}$.

Claudio Esteva ha estudiado con detalle el mercado de Chinchero entre los años 1969 y 1970 y describe los tratos de las compradoras y vendedoras en el mismo, de la forma siguiente:

«Las vendedoras se sientan en el suelo y lo mismo hacen las compradoras [...1 Llegan [las chincherinas] provistas de papas en cantidades que oscilan entre media arroba y una y media arrobas, según sus posibilidades [...] También suelen traer otras mercancías como habas tiernas y con vaina, recién cosechadas. Llevan las cargas en sus llijllas y suelen arrodillarse frente a la puestera [...] al comienzo la chincherina se limita a sentarse frente a la puestera y sin exhibir su mercancía se la ơferece diciéndole; «dame para mi chuño» o «para mi papa». Entonces la puestera contesta: «¿cuánto quieres?». A esa pregunta sigue por parte de la puestera, una puesta, por ejemplo de tres plátanos sobre el lienzo. A seguido la chincherina coloca sobre éste una cantidad de papas con valor considerado equivalente a los plátanos. La puesta de papas se hace con las dos manos abiertas. En general, pone dos o más puestas de manos.

«Si esta medida le parece correcta a la puestera, la chincherina se limita a poner en su llijlla la mercancía que aquella le dió y se marcha a otro puesto en busca de otros artículos [...] De este modo, todas las compras y ventas de alimentos suelen hacerse en pequeñas cantidades cuya medida máxima es, habitualmente, hasta cuatro manos dobles de algún artículo...

\section{$[\ldots]$}

«Las formas de negociar son aparentemente sencillas pero a partir de la puesta de papas o de habas por parte de la chincherina, la puestera suele reaccionar siempre exigiendo una cantidad adicional de papas, considerando que es insuficiente la que le es ofrecida. Uno de los argumentos más frecuentes consiste en decir ésta a la compradora que sus

38 Bernabé Сово [35] vol. II, p. 25, lib. XI, cap. 8.

R. I., $1999, \mathrm{n}^{\circ} 215$ 
papas son demasiado pequeñas y no alcanzan el valor de lo que dió a cambio. Comunmente, el acuerdo es rápido pues la compradora añade una o dos papas, o tres o cuatro y la operación concluye sin más dilaciones. Ese se hace incluso sin mirar directamente la vendedora a la compradora, pues todo radica en la costumbre de añadir que se concreta en una palabra mágica: aumento...» ${ }^{39}$

Como se aprecia fácilmente, comparando los textos antes transcritos, el sistema de regateo adquiere formas muy particulares y adecuadas al carácter de la población andina y, en cualquier caso, el comportamiento de compradores y vendedores con más de tres siglos de diferencia es muy similar.

El término nahuatl tianquiztli, plaza del mercado, en el mundo mexica, ha incorporado al castellano la palabra tianguez o tianguis, mexicanismo que significa «mercado» o «plaza» y que en los textos de los cronistas españoles llegó en la práctica a universalizarse, compitiendo solamente en época tardía con los términos quechuas: catucona, catar o ketu (Fray Domingo de Santo Tomás y Diego Gonçalez Holguin) o con el aymara ccatu (Ludovico Bertonio), para significar en el área andina «mercado», «feria» o «lugar donde se merca» ${ }^{40}$. Con alguno de esos términos, cronistas como Acosta, Cieza de León, Matienzo, Montesinos, Ortiz de Zúñiga y Atienza, designan la existencia general de mercados en tierras del Tahuantinsuyu ${ }^{41}$. Sin embargo, algunos de los escritores del siglo XVI precisaron la existencia de ferias y mercados en lugares concretos como Jauja, Cuzco, Quito, Císcala y entre los quijos del Oriente ecuatoriano ${ }^{42}$. De todos ellos, nos interesa destacar aquí el de Císcala, del que tenemos una referencia muy precisa debida a Carranza:

«Hay un pueblo que se llama Císcala que tiene paz con todas las demás provincias y aquel pueblo es seguro a todos y allí se hacen ferias o mercados y los Tacamas traen oro y esmeraldas a vender y los Campaces y Pidres (?) llevan sal y pescado y los Belinquiamas llevan ropa y

39 Claudio Esteva Fábregat [29], pp. 235-36.

40 Roswith HARTMANN, «Mercados y ferias prehispánicos en el área andina», Boletín de la Academia Nacional de Historia, Vol. 54, $\mathrm{n}^{\circ}$ 118, Quito, 1971, pp. 214-235, [pp. 215 y 227-28].

41 Ibidem, p. 215.

42 Ibidem, pp. 215-18. 
algodón y hacen allí sus mercados [...] Todas estas tierras se incluyen desde Pasao hasta el río de San Juan por la costa... ${ }^{43}$.

Aunque este pueblo de Císcala no se ha podido localizar, debe situarse en la zona del cabo San Francisco a juzgar por la presencia de los pueblos campaces y atacames, los cuales no debían hallarse lejos del lugar ${ }^{44}$. Del texto transcrito me interesa destacar el dato de que «tienen paz con todas las demás provincias y aquél pueblo es seguro a todos», lo que confirma la existencia de un estado de guerra interétnico casi continuo y por otro lado implica la necesidad de tener un lugar «pacificado» para el buen desarrollo de las relaciones comerciales llevadas a cabo en aquél mercado.

La imperiosa necesidad de un lugar neutral y pacífico para establecer relaciones comerciales entre grupos hostiles se ha observado en numerosos lugares en todo el mundo. Entre los bereberes «los mercados son los lugares donde se desarrollan los contactos externos y donde la estrecha solidaridad de grupo cerrado propia de la vida de aldea deja paso una conducta más libre que es consecuencia del intercambio de mercancías y experiencias con individuos que pertenecen a otros grupos, Así, el aislamiento cantonal tiene su contrapeso y su válvula de escape en la actividad de mercado ${ }^{45}$.

Aunque el tema de la guerra y la paz, lo trataremos en próximas páginas, es conveniente citar aquí algunos ejemplos de mercados neutrales o pacificados por acuerdos previos. Refiriéndose a los lencas Torquemada dice que «se hacían guerra y se arrebataban y quitaban sus heredades y no estaban seguros sino quando avía sus paces, acordadas en ciertos tiempos del año, que duraban y las contrataciones de aves, mantas, plumas, sal, cacao y achiote» ${ }^{46}$.

43 Martín DE CARRANZA, «Relación de las provincias de Las Esmeraldas que fue a pacificar el capitan Andrés Cordero», Relaciones Geográficas de Indias, Vol. 3: CXXXIVCXXXIX, Madrid, 1897 [1569], p. CXXXIX.

44 J. Alcina y Remedios de la PEÑA, «Etnias y culturas en el área de Esmeraldas durante el periodo colonial español», Ier. Congreso Español de Antropología, 11, Barcelona, 1980, pp. 327-41.

45 Karl Polanyi; C.M. ARensberg y H.W. Pearson [25], p. 247.

46 Juan DE TORQuemada, Monarquía Indiana, 3 Tomos, México, Salvador Chavez, 1943, T. I, p. 335.

R. I., $1999, \mathrm{n}^{\circ} 215$ 
TABLA 1. Mercados de trueque en América.

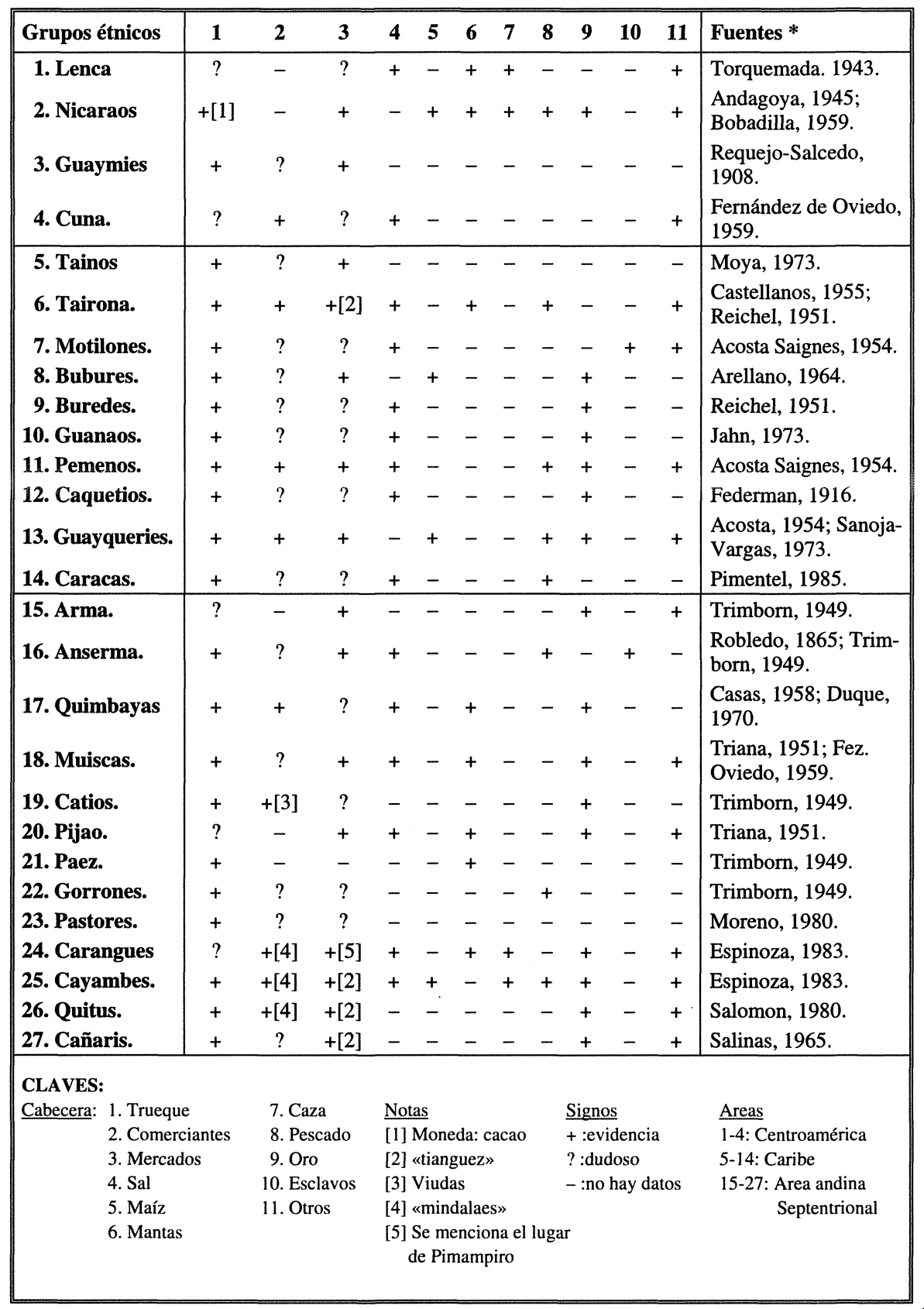


* El desarrollo de las siglas bibliográficas utilizadas como fuentes de esta Tabla es el siguiente:

Miguel ACOSTA SAIGNES, et al: Historia de la cultura en Venezuela, Caracas, Universidad Central de Venezuela, 1954; Pascual de AnAdagoya: Relación de los sucesos de Pedrarias d'Avila en las provincias de Tierra firme o Castilla del Oro, Colección de los Viajes y descubrimientos que hicieron por mar los españoles (Fernández de Navarrete de) Tomo III: 387-443, Buenos Aires, 1945; Antonio ARELlANo Moreno, Relaciones Geográficas de Venezuela, Biblioteca de la Academia Nacional de la Historia, Caracas, 1964; F. de Bobadilla, Historia General y Natural de las Indias, Islas y Tierra Firme del Mar Oceáno, Tomo IV. lib. 42, Madrid, 1959; Fr. B. de las CASAS, Apologética historia de las Indias, Madrid, Biblioteca de Autores Españoles, Tomo CVI, 1958; Juan de CastellaNos, Elegías de varones ilustres de Indias, Bogotá, Biblioteca de la Presidencia de Colombia, Vols. 9-12, 1955 [1601]; Luis DUQUE GóMEZ, Los Quimbayas, Bogotá, Instituto de Antropología, 1970; Valdemar EsPINOSA SORIANO, Los Cayambes y Caranques: siglos XV-XVI. El testimonio de la Etnohistoria, Otavalo, Instituto Otavaleño de Antropología, Colección Pendoneros: 61 y 62, 1983, Nicolás FEDERMAN, Relación del primer viaje a Venezuela, Caracao, Academia Nacional de la Historia, 1916; Gonzalo FERNÁNDEZ DE OVIEDO, Historia general y natural de las Indias, Madrid, 1959; Alfredo $\mathrm{J}_{\mathrm{AHN}}$, Los aborígenes del occidente de Venezuela, Caracas, Monte Avila eds. 1973; E. MoRENo: Historia de la penetración española en el sur de Colombia. Etnohistoria de Pastos y Quillacingas.Siglo XVI, Madrid, Editorial de la Universidad Complutense, 1980; Frank MoYA, «La sociedad taina» Cuadernos de Historia Dominicana, Santo Domingo, 1973; G. ReICHEL-DolmatofF, Juan, Datos histórico-culturales sobre las tribus de la antigua gobernación de Santa Marta, Bogotá, 1951; Juan REQUEJO-SALCEDO, Relación histórica y geográfica de la Provincia de Panamá. La reducción de Guayuri, Colección de Libros y Documentos referentes a la Historia de América, Madrid 1908; J. RoBlEDo, «Descripción de los pueblos de la provincia de Ancerma», Codoin, tomo III, Madrid, 1865; Juan SALINAS DE LoIOLA, «Relación y descripción de la ciudad de Loxa», Relaciones Geográficas de Indias, Perú, Madrid, 1965, Tomo II: pp. 291-306, [1582]; F. SAlomón. Los Señores étnicos de Quito en la época de los Incas, Otavalo Instituto Otavaleno de Antropología, Colecc. Pendoneros: 10, 1980; Mario SANNA e Iraider VARGAS, Antiguas formaciones y modos de producción, Caracas, Monte Avila eds. 1978; Fco. Juan de TORQuEMADA, Monarquía indiana. 3 tomos, México, Salvador CHÁvEZ, 1943; M. TRIANA, La civilización Chibuha, Bogotá, 1951; H. TRIMBORN, Señorío y barbarie en el Valle de Cauca, Madrid, CSIC, Instituto «Gonzalo Fernández de Oviedo», 1949.

La existencia de mercados en los estados antiguos ha sido estudiada por numerosos autores y comprobada en multitud de lugares 47 , lo que no es el caso de las jefaturas. En una reciente investigación sobre estas últimas en Centroamérica, el Caribe y el Area Andina Septentrional hemos podido comprobar (Tabla 1) que sobre un total de 27 sociedades hay datos que confirman la existencia de mercados en quince, se habla de trueque en 22 sociedades y existen datos concretos sobre la existencia de comerciantes en nueve de ellas, lo que nos permite afirmar con cierta seguridad que en todos esos grupos

47 Henri J. M. ClAESSEN, «The Early State: A Structure approach», The Early State, (Claessen-Skalnik, eds.), The Hague, 1978, pp. 533-596, [p. 543].

R. I., $1999, \mathrm{n}^{\circ} 215$ 
étnicos para los que estamos postulando su carácter de jefaturas había mercados o se practicaba el trueque, como forma de comercio institucionalizado. En cuanto a los productos intercambiados hay que llamar la atención sobre la notable incidencia de la sal y el oro, frente a los demás productos que mencionan las fuentes utilizadas.

\section{LOS SANTUARIOS.}

Para completar la definición del complejo del que estamos tratando en estas páginas, debemos referirnos ahora al tema de los santuarios y las peregrinaciones en el área andina. La proyección contemporánea de esta tradición prehispánica empieza a tener un creciente interés en nuestros días ${ }^{48}$, por lo que en un próximo futuro puede esperarse un más profundo conocimiento del tema. Aquí mencionaremos algunos ejemplos que podemos considerar como sobresalientes para entender el caso más específico en la región septentrional del área que es la que ahora nos interesa. En conjunto vamos a hacer referencia al santuario de la isla del Sol, en el lago Titicaca, Pachacamac en la costa, Chavín de Huantar, en el Callejón de Huaylas, al Santuario de Pariacaca en la Cordillera Marítima Central, a Noquip, en el Norte y ya en el Area Andina septentrional, a la isla de La Plata, frente a la costa de Manabi y La Tolita, en Esmeraldas (Ecuador). En realidad, «dentro de la idiosincrasia de los pueblos andinos se distingue el gusto por las peregrinaciones religiosas a prestigiosos adoratorios o a reconocidos oráculos ${ }^{49}$ de los que los citados podían ser, en algún sentido, los más famosos de la época prehispánica.

El más antiguo, o uno de los más antiguos, sin embargo, debió ser el de Chavín de Huantar que, según los datos que nos proporcionan Estanislao Vega Bazán ${ }^{50}$ y Vázquez de Espinosa ${ }^{51}$ sería una de

48 Deborah Poole, «Los santuarios religiosos en la economía regional andina (Cusco)». Allpanchis, Vol. 19, Cuzco, 1982. Mitchael J. SALINOW, «La peregrinación andina», Allpanchis, Vol. 7, Cuzco, 1974.

49 María Rostworowski, Historia del Tahuantinsuyu, Lima, Instituto de Estudios Peruanos, 1988, p. 274.

50 Estanislao VEGA BAZÁN, «Testimonio de una idolatría muy sutil que el demonio avia introducido entre los indios de las provincias de Conchucos y Guamalles», Duviols, Lalutte contre les religions autochtones dans le Pérou colonial. L'extirpation de l'idolâtrie entre 1532 et 1660, Lima, Isntitut Français d'Etudes Andines, 1971, pp. 386-89. 
las más importantes huacas de la sierra central y norcentral. Los templos que describen estos autores y que Duviols ${ }^{52}$ identifica con las ruinas de Chavín, serían la residencia del dios Huari «que fue un templo y oráculo muy célebre, situado en la provincia de Conchu$\cos »^{53}$.Vega Bazán decía «que era común adoratorio de los indios, todo debajo de tierra con unos callejones y laberintos muy dilatados hechos de piedras muy grandes y muy labradas» ${ }^{54}$. Según Vázquez de Espinosa ${ }^{55}$ : «era guaca y santuario de los más famosos de los gentiles como entre nosotros Roma y Jerusalem [y el demonio] les declaraba muchos oráculos y así acudían de todo el Reyno».

«Otro ejemplo de centro ceremonial -nos dice Maria Rostworowski ${ }^{56}$ al cual se dirigían peregrinos de diferentes condiciones sociales en determinada época, fue el pueblo de Ñoquip, cerca de Chérrepe, en el norte. El lugar estaba rodeado de ciénagas y de cerros huacas, habitualmente poseía escasa población compuesta por agricultores y pescadores. Sin embargo, al tiempo de celebrarse sus fiestas rebosaba el villorrio de visitantes, tanto de hombres del común como de gente muy principal. Todos juntos realizaban sus antiguos ritos acompañados de bailes y cantos».

El más famoso de los santuarios del Area Andina Central fue, sin embargo, el de Pachacamac, el dios costero por excelencia y Señor de los movimientos telúricos. «A su templo acudían numerosos fieles y sus ofrendas llenaban los extensos depósitos del santuario» ${ }^{57}$. El prestigio de este santuario se debía especialmente a sus famosos oráculos. «Cieza de León menciona las grandes romerías que se realizaban en honor del dios Pachacamac en cierta época del año. La gente acudía de lejanos parajes y se acomodaban en amplios aposentos preparados para tal propósito» ${ }^{58}$.

\footnotetext{
51 Antonio VÁZquez de EsPINOSA, Compendium and description of the West Indies, Washington, Smithsonian Miscellaneous Collection, 1942, [1629].

52 Pierre Duviols, «Huari y Llacuaz. Agricultores y pastores. Un dualismo prehispánico de oposición y complementaridad», Revista del Museo, Vol. XXXIX, Lima, 1973, pp. 153-191, [p. 157].

53 Ibidem.

54 Estanislao VEGa BAZÁN, [50].

55 Antonio VÁZQUEZ DE ESPINOSA, [51].

56 María RosTwOROWSKI, [49], p. 295.

57 María RosTWOROWSKI, Estructuras andinas del poder. Ideología política y religiosa, Lima, Instituto de Estudios Peruanos, 1983, p 42.

58 María RosTwOROWSKI, [49], p. 274.
} 
Pariacaca era otro importante santuario situado en la Cordillera Marítima Central a donde acudían en peregrinación desde numerosas regiones de la costa para celebrar sus fiestas ${ }^{59}$.

En el territorio del Area Andina Septentrional, Jorge G. Marcos y Presley Norton ${ }^{60}$ han sugerido que la isla de La Plata «funcionó como un centro ceremonial tan temprano como Valdivia III y también como un centro de intercambio y continuó de esa manera a través de las fases Machalilla, Chorrera, Bahía y Manteño». Los guardianes del santuario han debido funcionar como sacerdotes-shamanes y como mercaderes en un comercio marítimo que podría haber alcanzado las costas de Mesoamérica teniendo como materia prima de intercambio la apreciada concha del Spondylus.

El caso de La Tolita es, al igual que el de La Plata, el de un santuario y posiblemente un puerto de intercambio internacional de larga tradición, ya que se desarrolla desde el Formativo ${ }^{61}$. Se trata de un conjunto de tolas o montículos de gran tamaño que, evidentemente, constituyen un centro ceremonial ${ }^{62}$ con una alta concentración de material de carácter suntuario, cuyo saqueo se inicia en 1600 , pero que aún conserva en la actualidad una gran cantidad de materiales arqueológicos. En la narración que se ha conservado de la expedición de Pedro de Arévalo en 1600 por el río Santiago se habla de que un tal Francisco de Arobe dijo de La Tolita que:

«...antiguamente auía sido población y de donde los yndios de toda aquella tierra subjectos a los dichos mulatos y los de la provincia de cayapa combocanos y otros de la dicha costa sacaban e iban a sacar mucho oro y no porque la tierra lo cría ni el rrio estrae más que al dicho capitán pedro de aréualo le pareció que era oro labrado y que lo auía por auer sido antiguamente como dicho tiene población y oratorio y habitádola muchos yndios plateros...» ${ }^{63}$.

\footnotetext{
59 Ibidem.

60 Jorge G. MARCOS, y Presley NORTON. «Interpretación sobre la arqueología de la isla de La Plata». Miscelánea Antropológica Ecuatoriana, Guayaquil, 1981, Vol. 1, pp. 136-154, [p. 49].

61 J. F. BOUCHARD, «Programme La Tolita», Equipe de Recherche 313: Prehistoire de Regions Andines. Rapport d'activitè 1984-87, 44-56, París, CNRS, 1987, p. 44 y Francisco VALDEZ, Proyecto arqueológico «La Tolita» (1983-1986), Quito, Museo del Banco Central, 1987.

62 Francisco ValdeZ [59], p. 18, fig. 8.

63 José Rumazo GonZaleZ, Colección de Documentos para la Historia de la Audiencia de Quito, 8 vols, Madrid, Afrodisio Aguado, 1949, Vol. IV, p. 32.
} 
De acuerdo con esta descripción, el santuario que suponemos era La Tolita, concentraba al menos una amplia población de artesanos que junto con los sacerdotes-shamanes, los señores y su parentela, nobles y servidores constituirían la población permanente del centro ceremonial, mientras los agricultores y pescadores podrían situarse probablemente en las inmediaciones del asentamiento.

El carácter de santuario de este sitio quedaría confirmado por un dato de Miguel Cabello Valboa quien se refiere a un lugar sagrado que podría ser, en nuestra opinión, La Tolita:

«Entre la bahía de San Mateo y Ancón de Sardinas hay un pequeño río, el cual los caribes de aquellas riberas tienen por adoratorio y santuario y traen oro en polvo de la tierra adentro metido en unos canastillos delgados y haciendo sus oraciones, cuales ellos son, lo derraman en él; en aquella parte están de guarnición cien indios o más, sustentados por los de la Provincia y éstos se mudan a tiempo y defienden bien su partido» 64 .

Con independencia de la confirmación de La Tolita como santuario, lo más importante del dato reseñado de Cabello es el hecho de que la paz del lugar está garantizada por la presencia de una guarnición de un centenar de indios a los que «sustentan» los de la provincia, es decir, los grupos tribales o las jefaturas de toda la región. Este dato queda confirmado por otro, muy tardío, que se contiene en el Título de Gobernador de Pedro Maldonado, de 1747. En ese título, conservado en el Archivo Nacional de Historia (Sección de Gobierno), hay una cláusula que dice:

«En el Capítulo Séptimo propusisteis se estableciera y mandase que los indios del Pueblo de Cayapas (que son cincuenta) desde diez y ocho hasta cincuenta años de edad, pagasen tributo [...] teniendo presente hacia cien años poco más o menos que estos Indios salieron a Quito buscando asilo, para defenderse de los Malabas, sus contrarios [...] quedaron desde entonces obligados a poner centinelas todos los meses en la Playa del Mar, remudándose de doce en doce».

A pesar de la diferencia de fechas, se aprecia la existencia de una tradición que se continúa durante casi doscientos años: el dato de

64 Miguel Cabello Valboa, «Verdadera descripción y relación de la provincia y tierra de las esmeraldas», Obras de M.C.V. 1945, [1583], Vol. 1, Quito, pp. 1-96, [p. 15].

R. I., $1999, \mathrm{n}^{\circ} 215$ 
Cabello es de 1583 y el texto de Maldonado se refiere a 1647 y 1747. El lugar es, posiblemente, el mismo - entre la bahía de San Mateo y Ancón de Sardinas o en la «playa del mar»- y el procedimiento es el mismo: centinelas - un centenar o doce- que sustentan los indios de la provincia o los cayapas. En el texto de Cabello se especifica muy claramente cuál es la función de estos centinelas: «defender bien su partido», o sea, el santuario.

\section{GUERRA Y PAZ.}

En la medida en que estamos considerando que el complejo «santuario-mercado-festival» se presenta en el marco de las jefaturas, el cuadro de relaciones interétnicas previo a esa situación es lo que podríamos llamar la «guerra tribal» generalizada. Con independencia de que tal estado de guerra sea un sistema de control de la población como defiende ${ }^{65}$ o que la presión demográfica conduzca a la guerra ${ }^{66}$ el hecho real es que esa guerra tribal generalizada no acaba tampoco con la constitución de las jefaturas, aunque el hecho de que las «milicias» que acompañan al jefe como «guardia pretoriana» o se emplee en raids o razzias contra otros grupos, hace variar sustancialmente los objetivos de la guerra que ahora son, preferiblemente, de carácter económico, más que responden a motivos de venganza por asesinatos, caza furtiva, brujería o rapto de mujeres ${ }^{67}$ como ocurriera en el estado tribal. Cabe señalar, sin embargo, que el origen y la elevación de los grandes hombres, puede proceder del prestigio que los grandes guerreros han adquirido en la guerra tribal ${ }^{68}$.

Debe advertirse en relación con el papel de la guerra tal como se argumenta en este ensayo, que no es nuestro propósito examinarlo en términos de su papel como motor para la consolidación o nacimiento del Estado ${ }^{69}$. Por el contrario nuestro propósito ha sido con-

\footnotetext{
65 Marvin HARRIS,. Vacas, cerdos, guerras y brujas. Los enigmas de la cultura, Madrid, Alianza, El Libro de bolsillo: 755, 1980, pp. 64-68

66 Andrew P. VAYDA, «Guerra y paz en Nueva Guinea», Cultura y Ecología en las Sociedades Primitivas, Barcelona, (Buxó ed.) 1983, pp. 187-221, [p. 191].

67 Idem.

68 Maurice Godelier, La producción de Grandes Hombres. Poder y dominación masculina entre los baruya de Nueva Guinea, Madrid, Akal, 1986.

69 Robert L.CARNEIRO, «A theory of the origin of the State», Science. Vol. 169, New York, 1970, pp. 733-38. «Political expansion as an expression of the principle of competiti-
} 
siderar el estado de guerra intertribal en su relación con la existencia del mercado internacional y la existencia de santuarios y peregrinaciones en un medio social y político en el que la mayor parte de los grupos étnicos se hallaban en el nivel de las tribus o en el proceso de consolidación de las jefaturas. En definitiva, la hipótesis que estamos desarrollando en estas páginas trata de examinar las tendencias cooperativas de las sociedades antiguas más que las tendencias de competencia entre ellas.

Lo que se puede inferir de los datos mencionados hasta ahora y del cuadro general en el que nos estamos moviendo, podría dar como resultado el complejo «santuario-mercado-festival» al que se refiere este ensayo. Tal como ocurría en la costa de Esmeraldas, o más al sur, en la regíón de Manta, pero posiblemente en otros muchos lugares de la region, ya fuese en la costa o en el altiplano, había una multitud de grupos étnicos, muchos de los cuales estarían organizados en la forma tradicional de las tribus, pero de los que comenzarían a destacar algunos, concentrando una mayor población y una mayor densidad demográfica, mayor poder político, con cierto número de villas, en algunas de las cuales comenzaría a fortalecerse algún santuario, con mayor renombre internacional, al que comenzarían a acudir en peregrinación, gentes de procedencia diversa dentro del área. Esos grupos étnicos - tribus o jefaturas incipientes- estarían enzarzados en continuas luchas en las que se reproducirían las clásicas enemistades entre familias, linajes o clanes. Disponiendo algunos caciques de una incipiente milicia, una especie de guardia personal a su servicio, habrían podido llegar a «acordar» con otros caciques emparentados o amigos, el establecimiento de ciertas zonas de seguridad en las que los enfrentamientos intergrupales estuviesen proscritos.

Los casos de Ciscala o de La Tolita podrían ser los ejemplos característicos para el caso de un mercado el primero o de un santuario el segundo. En nuestra opinión, aunque esa disociación se puede producir, si tenemos en cuenta algunos casos que hemos mencionado en las páginas anteriores, el modelo debe incluir esos dos factores o as-

ve exclusión», Origins of the State, Philadelphia, (Cohen-Service eds.) 1978, pp. 205-223. D. WEBSTER, «Warfase and the evolution of the State: a reconsideration», American Antiquity, vol. 40: 465-70, Salt-Lake City, 1975 o David J. WILSON: «The origins and development of complex prehispanic society in the lover Santa valley, Perú: implications for theories of state origins», Journal of Anthropological Archaelogy, Vol. 2, 1983, pp. 209-76.

R. I., $1999, \mathrm{n}^{\circ} 215$ 
pectos combinados, sin que se pueda decir cuál de los dos es el primero en el tiempo y, por consiguiente, causa del otro. Un mercado puede haber promovido el surgimiento de un templo o santuario o al revés.

Un lugar sagrado o Santuario con ferias o mercados a los que concurrirían los indios de la región con sus materias primas o sus productos manufacturados e incluso cierto tipo de mercaderes, sería el lugar más adecuado para la celebración de festivales en los que se produciría la necesaria redistribución de bienes que permitiría el reforzamiento del linaje del cacique o soberano en su posición de árbitro, como Gran Guerrero o Sumo Sacerdote, con el ganado prestigio por sus hazañas en el campo de batalla o por sus milagros en el terreno de la brujería, ante el conjunto de naciones, tribus o pequeñas jefaturas que vendrían a encontrarse en ese lugar. No es necesario pensar en festivales tan complejos o dilapidadores, como fuera el potlatch para los indios del Noroeste, pero indudablemente esas fiestas permitirían que el Señor regalase a parientes y amigos comida y distinciones de carácter suntuario - de ahí la necesidad de esa población de «plateros»- o de otro tipo no detectable en el registro arqueológico.

Teniendo en cuenta todo lo que hemos venido diciendo en las páginas precedentes, consideramos que la figura del centro ceremonial es la primera forma de urbanismo que podemos detectar en la región y que esa formulación urbanística se da en combinación con la existencia de mercados de intercambio internacional, en un lugar en el que el cacique, o los caciques de la zona han creado un área de seguridad o de paz. El desarrollo posterior del urbanismo implicará otra serie de transformaciones y cambios, de los que la forma final, sin duda, será la integración del centro ceremonial en la ciudad, según el modelo del altiplano central de México.

This article studies the origins of urbanism in the Andean Area. It contends that urbanism takes form in the "ceremonial centers», considered as original and alternative cities whose origins have to do with their being places where a sort of concerted, «international» peace is achieved. Those centers assemble religious (a sanctuary) and economical (a market) interests. They are also used as sites for festival celebrations with multiple aims such redistribution, exogamy, etc. 